\title{
O "EGO" DESEJANTE: UMA LEITURA POSSÍVEL DE A TERCEIRA MARGEM DO RIO, DE JOÃO GUIMARÃES ROSA
}

ROSA, João Guimarães. A terceira margem do rio. Primeiras estórias, v. 14, p. 32-37, 1988.

A literatura de João Guimarães Rosa é aquela margem universal, porque parte justamente de um microcosmo regional. Afinal, as inquietações dos sujeitos, suas consciências identitárias, suas conturbações para o "além mais" do real, são irmãs de toda a humanidade.

Nessa resenha, exploraremos as possibilidades de leitura do conto A Terceira Margem do Rio, de João Guimarães Rosa, na intermitência de figurar a questão do destino, tratada já pelos gregos em sua história, cultura e, inclusive, arte literária, a partir da contraposição entre as categorias de subordinação e de decisão. Utilizar-se-á a Teoria da Literatura (BENJAMIN, 1994; COUTINHO, 2004; D’ONOFRIO, 1995; SOARES, 1998) e as Ciências Psicanalíticas (FREUD, 1996; KEHL, 1990; LACAN, 2005) como foco e escopo de análise.

Há no conto de Rosa, uma personagem alcunhada pelo próprio narrador, apenas como pai. O destino dessa personagem parece único e unificado em detrimento de sua colocação semântica (o pai) no enredo, isto é, o imaginário e o simbólico coletivo pré-posicionam tal personagem a uma imagem social paterna. $\mathrm{O}$ pai ${ }^{2}$ do conto em questão, entretanto, desapossase do estatuto sociocultural de pai, na medida em que decide proteger-se da calcificação de seu status conhecido e estável, buscando esterilizar-se do caos da consciência de ser apenas um acordo entre testemunho do desígnio de uma família. Assim, não de subordinação, pelo contrário, opta por se isolar e se esquivar da responsabilidade sociocultural (imaginária e simbólica) de deter o poder de transformação da prole, colocando-se em um lugar afastado, por exemplo, do estereótipo de masculino como provedor do lar.

\footnotetext{
${ }^{1}$ Universidade Federal de Santa Maria (UFSM), Santa Maria - Rio Grande do Sul - Brasil. Mestre em Estudos Linguísticos, pelo Programa de Pós-Graduação em Letras da Universidade Federal de Santa Maria (UFSM). Trabalha atualmente no projeto de pesquisa Núcleo de Capacitação em Desenvolvimento de Recursos em Ensino de Língua Portuguesa (CADRELP) na UFSM, o qual tem por finalidade a formação docente triangulada entre academia, mercado e licenciandos. ORCID <http://orcid.org/0000-0003-1718-7011>. E-mail: feletras2007@hotmail.com.

${ }^{2}$ Durante o texto, a palavra pai será apresentada no masculino e no feminino. No masculino quando tratado enquanto pessoa e no feminino enquanto tratado enquanto personagem (seguindo as normas na narratologia).
} 


\section{Linguagens - Revista de Letras, Artes e Comunicação - ISSN 1981- 9943 \\ Blumenau, v. 13, n. 3, p. 516-520, set./dez. 2019 \\ DOI: http://dx.doi.org/10.7867/1981-9943.2019v13n3p516-520}

A atitude do pai transversaliza-se pelos níveis fundamentais do psicologismo humano, já que tendo consciência da sua funcionalidade paternal para os desígnios da esposa e dos filhos, ele procura na neutralidade, o abrandamento da sua condição de vicissitude para com os outros e torna-se matéria nata de seus próprios anseios. Somente ao anular-se é que o pai se faz equilíbrio no destino dos seus familiares. Trata-se aqui, não mais da interdição do desejo, em termos freudianos, uma vez que uma necessidade interna do Ego se descarrega em forma de movimento, ou ação. Assim como o bebê faminto chora por fome, o pai do conto de Rosa coloca seu "Eu" particularizado em primeiro plano ao seu "Eu" coletivo, segundo Kehl (1990) e Lacan (2005).

Levando-se em conta a Teoria da Literatura, pode-se afirmar que o nível actante da personagem "pai" na narrativa em análise vai ao encontro do seu psicologismo individual. Desse modo, na narratologia, a personagem "pai" é "sujeito de uma ação, é quem sente falta de algo e inicia um processo de transformação para possuir o objeto desejado; objeto é a coisa desejada, o valor de que se sente falta." (D’ONOFRIO, 1995, p. 89).

Por conseguinte, a personagem "pai" do conto de Rosa anula-se do cotidiano, mas não se torna amorfo, na medida em que sua funcionalidade como partícipe da narrativa não se perde totalmente. $\mathrm{O}$ ato de o pai manter-se em uma canoa, em um rio, "de meio a meio", evidencia que ele somente se extraiu do seio imaginário e coletivo da sua família, para ser um ator real da posição prescritiva de sucessão dada a seu filho.

Há de se salientar que o espaço físico e que o espaço psicológico estão particularmente unidos, já que a paisagem exterior (calcada na imagem e na significação do rio) funde-se à paisagem interior (calcada na psique do pai, que se pretende inócua quando da sua decisão de permanecer em uma canoa no rio). Angélica Soares, ao enquadrar o tipo de foco narrativo, explicita-nos que um desses pode ser chamado de focalização homodiegética "em que o narrador participa como agente da diegese narrada" (SOARES, 1998, p. 53). Assim, no conto de Rosa, observa-se essa tipificação quanto ao foco da narrativa, uma vez que é o filho quem assume o papel de narrador, e também, é uma das personagens. Quando o filho toma a palavra do pai, que já era silêncio na canoa no meio do rio, ele toma, também, o espaço imaginário e simbólico do pai, contudo, ainda não compreende a atividade real realizada pelo pai para que esse nível sociocultural de transposição de lugares sociais (familiares no caso; o provedor) se efetive.

A consciência (desejo, pulsão, Ego) do pai se reflete em sua ação (real). O pai do conto torna-se o próprio rio do conto. Por necessidade de ser mistério, por necessidade de 


\section{Linguagens - Revista de Letras, Artes e Comunicação - ISSN 1981- 9943 \\ Blumenau, v. 13, n. 3, p. 516-520, set./dez. 2019 \\ DOI: http://dx.doi.org/10.7867/1981-9943.2019v13n3p516-520}

flutuar sozinho, por necessidade de ficar perplexo diante do mundo, por necessidade de transformar essa perplexidade em dádiva de (auto) conhecimento. O pai (do conto) é excludente porque se renega em sua imagem parental, mas é libertário porque aceita sua essência de ser humano real, com desejos reais e com atitudes reais. O pai da narrativa de Rosa, mesmo condicionado pelas construções socioculturais, quebra as contingências do tempo e do espaço e volta a ser o que sempre fora: o universo todo em si, a escalada de sua própria presença no mundo com um projeto heroico. Há uma descarga de excitação, pois o pai não aceita o recalque das suas mais instintivas moções de objetos de prazer. A esse respeito, Freud (1996) traz o conceito de princípio da realidade, no qual, o desejo, que antes era imaginário e simbólico, se transforma em objeto real, para evitar que a libido (deixar de ser a imagem parental da família) se projete como ansiedade.

É justamente essa a tensão do conto A Terceira Margem do Rio: o homem precisa da incomunicabilidade para existir e permanecer. É dessa incomunicabilidade que surge o conhecimento da grandeza do seu ser destarte às contingências dos outros. O que produz sentido para o Ego é a sua relação e a sua comunicação com os outros, entretanto, o sujeito desejante necessita eleger um percurso real e individual para, posteriormente, constituir-se como sujeito produtor de sentidos, sem os sentidos produzidos pelas semioses das suas intersecções com a sociedade (papel social pré-definido para o conceito de pai em uma família). A incomunicabilidade do pai (do conto) nada mais é do que força propulsora para a tentativa de comunhão para com sua família, haja vista que o imaginário e o simbólico serão trocados pelo real, logo, o conceito de família estará libado das modalidades conceituais e se calcará apenas no que é real. O pai liberta seu filho dessa imagem e desse papel social, dando-lhe uma condição humana, justamente, por lhe mostrar que o filho pode vir a tornar-se um ser individuado, ocupante de uma mesma "canoa": um sujeito soberano de suas próprias ações. Assim como o pai, que um dia fora herói de si ao abandonar a família e abrigar-se na sua condição de ser humano real, o filho terá a opção de escolher por também o ser.

O rio no conto de Rosa pode ser percebido como uma representação imagética. Segundo Maria Cecília Amaral de Rosa (2009, p. 99), rio está "relacionado com água fluente, é símbolo do tempo, do transitório e da constante renovação/os rios correm para o marsímbolo da união entre o individual e o absoluto." Parece crucial entender esse elo que se faz na narrativa por meio da simbologia do rio. Se o rio corre do extremo individual ao extremo absoluto, infere-se que o pai ilustra a própria simbologia rio, uma vez que o mesmo (o pai) amplia-se enquanto humano ao individualizar-se, e essa individualização é a força propulsora 


\section{Linguagens - Revista de Letras, Artes e Comunicação - ISSN 1981- 9943 \\ Blumenau, v. 13, n. 3, p. 516-520, set./dez. 2019 \\ DOI: http://dx.doi.org/10.7867/1981-9943.2019v13n3p516-520}

para que o filho consiga iniciar o seu processo de individualização (elemento fundante de suas próprias ações).

Se para Walter Benjamin (1994, p. 197) "as ações da experiência estão em baixa, e tudo indica que continuarão caindo até que seu valor desapareça de todo" então no conto de Rosa, existe um desalinho com essa concepção benjaminiana, visto que o narrador de $A$ Terceira Margem do Rio investe-se de sua própria experiência ativa para colocar-nos, leitores, diante de nossas próprias motivações, questionando-nos se somos frutos de um destino, ou de uma escolha.

O conto A Terceira Margem do Rio pode ser resumido como o seguinte axioma: o homem sábio acima de conceitos, pois:

[...] o narrador figura entre os mestres e os sábios. Ele sabe dar conselhos: não para alguns casos, como o provérbio, mas para muitos casos, como o sábio. Pois pode recorrer a um acervo de toda uma vida, uma vida que não inclui apenas a própria experiência, mas em grande parte a experiência alheia (BENJAMIN, 1994, p. 221).

Em suma, no conto A Terceira Margem do Rio, o pai acaba suprimindo-se da sua experiência como provedor (imagem parental) para mostrar seu desejo de individuação ao filho. Sendo o filho, o narrador do conto, cabe a ele extrapolar todo o sentido da vida do pai, e repensar a sua própria vida. Então, o "filho" narrador encontra sua impotência diante da impotência do pai, que é a impotência de cada ser humano. A impotência diante da condição de ser humano. A individuação coloca-se, portanto, como subsidiária da universalização, já que para nos individualizarmos, necessitamos primeiro, compartir com nossos pares imagens, papéis e lugares sociais. O Ego se faz pelo outro, assim como o "Eu" da instância da linguagem só existe pela sua relação com o "Outro" na e pela linguagem.

\section{REFERÊNCIAS}

BENJAMIN, Walter. O Narrador: considerações sobre a obra de Nikolai Leskov. Magia e técnica, arte e política: ensaios sobre literatura e história da cultura. São Paulo: Brasiliense, 1994, p. 197-221.

COUTINHO, Afrânio. A Literatura no Brasil. 7. ed. São Paulo: Global, 2004.

COVIZZI, Lenira Marques. O insólito em Guimarães Rosa e Borges. São Paulo: Ática, 1978.

D’ONOFRIO, Salvatore. Teoria do texto: prolegômenos e teoria da narrativa. 1. ed. São Paulo: Editora, 1995. 
FREUD, Sigmund. O Futuro de uma Ilusão, O Mal-Estar na Civilização e outros Trabalhos (1927-31). In: ESB, Obras Psicológicas Completas. Vol. XXI. Rio de Janeiro: Imago, 1996.

HOMERO. Ilíada. São Paulo: Martin Claret, 2004.

KEHL, Maria Rita. O desejo da realidade. In: NOVAES, Adauto (Org.). O desejo. São Paulo: Companhia das Letras, 1990.

LACAN, Jacques. O Simbólico, o Imaginário e o Real. Nomes-do-Pai. Rio de Janeiro: Jorge Zahar Ed., 2005.

ROSA, João Guimarães. A terceira margem do rio. Primeiras estórias, v. 14, p. 32-37, 1988.

ROSA, Maria Cecília Amaral de. Dicionário de símbolos: o alfabeto da linguagem interior. São Paulo: Escala, 2009.

SOARES, Angélica. Gêneros literários. São Paulo: Ática, 1998. 